\title{
Nonconscious goal pursuit: Acting in an explanatory vacuum
}

\author{
Gabriele Oettingen $^{\mathrm{a}, \mathrm{b}, *}$, Heidi Grant ${ }^{\mathrm{a}, 1}$, Pamela K. Smith ${ }^{\mathrm{a}, 2}$, Mary Skinner ${ }^{\mathrm{a}}$, \\ Peter M. Gollwitzer ${ }^{\text {a,c }}$ \\ ${ }^{a}$ New York University, USA \\ ${ }^{\mathrm{b}}$ University of Hamburg, Germany \\ ${ }^{\mathrm{c}}$ University of Konstanz, Germany
}

\begin{abstract}
Nonconsciously activated goals and consciously set goals produce the same outcomes by engaging similar psychological processes (Bargh, 1990; Gollwitzer \& Bargh, 2005). However, nonconscious and conscious goal pursuit may have different effects on subsequent affect if goal pursuit affords an explanation, as nonconscious goal pursuit occurs in an explanatory vacuum (i.e. cannot be readily attributed to the respective goal intention). We compared self-reported affect after nonconscious versus conscious goal pursuit that either violated or conformed to a prevailing social norm. When goal-directed behavior did not require an explanation (was norm-conforming), affective experiences did not differ after nonconscious and conscious goal pursuit. However, when goal-directed behavior required an explanation (was norm-violating), nonconscious goal pursuit induced more negative affect than conscious goal pursuit.
\end{abstract}

Keywords: Automatic goal pursuit; Conscious goal pursuit; Norm-violating behavior; Explanatory vacuum; Affective experience

With the increased interest in self-regulation (Baumeister \& Vohs, 2004), how people set and meet their goals has become an important research question (summary by Oettingen \& Gollwitzer, 2001). Many theorists assume that successful goal setting and goal implementation require conscious involvement (Bandura, 1997; Cantor \& Kihlstrom, 1987; Carver \& Scheier, 1981; Deci \& Ryan, 1985; Locke \& Latham, 1990). Some, however, have argued that successful goal pursuit may also run off completely (i.e., automotive theory, Bargh, 1990) or partly (i.e., strategic automaticity; Gollwitzer, 1999) nonconsciously.

The automotive model of nonconscious goal pursuit (Bargh, 1990) assumes that goals are mental representations that can be activated by features of the contexts in which those goals have been pursued often and consistently in the past. For example, if a person repeatedly and consis-

\footnotetext{
* Corresponding author.

E-mail address: gabriele.oettingen@nyu.edu (G. Oettingen).

1 Now at Lehigh University.

${ }^{2}$ Now at Leiden University.
}

tently has used parties to impress people, the goal of impressing others becomes automatically activated upon entering a party. It should become active even though the person may not consciously choose to impress others at that time and in that situation. The automotive model further assumes that once activated in this nonconscious manner, the mental representation of the goal would operate in the same way as when it is consciously activated. That is, the model predicts that a given goal has the same effects on cognition and behavior no matter whether it is automatically activated or consciously pursued.

\section{Nonconscious vs. conscious goal pursuits: Observed similarities}

Chartrand and Bargh (1996) tested automotive theory by activating the information processing goals of impression formation versus memorization via semantic priming procedures. They obtained effects on reaching these goals just as Hamilton, Katz, and Leirer (1980) did for the respective consciously set goals. Studies using a variety of other 
goals also observed that nonconsciously activated goals are as effective in producing desired outcomes as consciously activated goals. For example, priming the goal of achievement (i.e., to perform well) causes participants to score higher on verbal tasks than control-group participants (Bargh \& Gollwitzer, 1994; Bargh, Gollwitzer, Lee-Chai, Barndollar, \& Troetschel, 2001).

Goals can be activated (primed) outside of awareness by presenting relevant semantic concepts supraliminally or subliminally (e.g., the words of "strive" and "achieve" for the activation of the goal of achievement; Chartrand \& Bargh, 1996). Situational cues in the presence of which the goal has been frequently and consistently pursued in the past were also used as primes: participants were asked to take place behind an impressive desk to activate power goals (Chen, Lee-Chai, \& Bargh, 2001), reminded of significant others to activate goals geared towards impressing significant others or goals that these significant others have for the self (Fitzsimons \& Bargh, 2003; Shah, 2003), and asked to observe the goal pursuits of others (i.e., goal contagion effect; Aarts, Gollwitzer, \& Hassin, 2004). Even though some of these methods to activate goals (in particular the priming of relevant semantic concepts) have also been used to study perception-behavior effects, these methods have been shown to successfully activate goals outside of a person's conscious awareness (see Bargh et al., 2001, for a discussion of perception-behavior effects from a motivation perspective).

There is evidence that nonconsciously activated goals are not only equally effective as consciously set goals in guiding people towards goal attainment, but also operate on the basis of the same mechanisms. Since Lewin (1926) and Tolman (1925) goal pursuit is assumed to be characterized by a number of distinct features. These features are associated with conscious and nonconscious goal pursuits alike (Aarts et al., 2004; Bargh et al., 2001; Riketta \& Dauenheimer, 2003): persistence in the face of difficulties, resuming goal activity after disruption, searching for good opportunities to act on the goal and shunning bad ones, the dependence of goal strength on higher order needs, and the tendency of goal states to stay activated until the desired outcome is reached.

Similarities in conscious and nonconscious goal pursuits are also observed when the desired outcomes have been reached. Having reached a consciously set goal is commonly assumed to lead to positive self-evaluative thought associated with a positive mood (Atkinson, 1957; Gollwitzer, 1990; Heckhausen, 1977), and with setting more challenging subsequent goals (i.e., proactive goal setting; Bandura, 1997). As for reaching nonconsciously activated goals, Chartrand (2004; Chartrand and Bargh, 2002) conducted the following studies: Participants were nonconsciously induced (or not) to pursue achievement or impression formation goals that then turned out to be either easy or difficult (i.e., led to good performance versus moderate performance). Nonconscious goal striving led to better moods and higher achievements in subsequent tasks in the easy task as compared to the difficult task condition, whereas no such differences were found for participants who did not pursue a goal (control participants).

\section{Nonconscious vs. conscious goal pursuits: Hypothesized differences}

People who consciously strive for a goal can readily explain their striving for and achieving of certain outcomes by referring to the consciously held goal. Such easy understanding by pointing to a goal (one's conscious intention) is not possible in the case of nonconscious striving, however, and thus the causes of one's actions and produced action outcomes should remain obscure. Recent research speaks to this explanatory vacuum. Chartrand, Cheng, and Tesser (2001; Chartrand and Bargh, 2002) point out that nonconsciously striving individuals should not only have difficulties to explain their goal-directed behaviors and achieved outcomes, but also the positive and negative moods associated with suffered failures and achieved successes, respectively (i.e., they should experience "mystery moods"; Chartrand, 2004). In accordance with the postulate by Tesser, Martin, and Cornell (1996) that unexplained more so than explained negative moods lead to self-defensiveness, they observed that participants with nonconscious achievement goals self-enhanced more after failure than those with conscious achievement goals. Most interestingly, when a simple reason for the experienced negative mood was provided, these effects disappeared.

If conscious goal pursuits allow for ready explanations of goal-directed actions and their consequences, whereas nonconscious goal pursuits leave goal-directed actions and their consequences unexplained, psychological functioning should differ between individuals who are engaged in conscious vs. nonconscious goal pursuits whenever there is some explaining to do with respect to the goal striving at hand. For example, behaviors which do not fulfill social norms demand an explanation, because without explanatory excuses one is confronted with the anger of others or one's own feelings of guilt and irritation (e.g., McGraw, 1987; Roseman, 1984; Wicker, Payne, \& Morgan, 1983; Weiner, Amirkhan, Folkes, \& Verette, 1987).

McGraw (1987) found that individuals experience the most guilt when they engage in accidental rather than in intentional transgressions. In a first study, participants were asked to read various vignettes (e.g., a man suffered a broken arm) in which it was varied whether harm was done accidentally or intentionally. When participants had to imagine themselves as harmdoers, they vicariously experienced more guilt for accidental as opposed to intentional transgressions. In a second experiment, participants were asked to recall situations where they accidentally versus intentionally harmed somebody. When requested to indicate retrospectively how guilty they felt after the incident, it was again the accidental transgressions that produced stronger guilt than the intentional transgressions. These results are consistent with the transgression-compliance 
literature, where compliance (presumably in the service of guilt reduction; Freedman, 1970) reliably follows accidental transgressions (Freedman, Wallington, \& Bless, 1967), but not intentional transgressions (Noel, 1973). Apparently, if an intention to transgress has been formed the act can be readily justified.

These observations suggest that norm-violating behavior resulting from a nonconsciously activated goal should lead to more negative affect than norm-violating behavior resulting from a consciously held goal. The latter but not the former goal pursuit provides an easy explanation of that behavior. The behavior can be explained by referring to the conscious intention to violate the norm.

\section{The present experiment: Behaving the same, but feeling differently}

We examined the affective consequences of nonconscious and conscious goal pursuit that either violates or does not violate a prevailing social norm. We asked participants to work together on a joint task (i.e., writing stories together with another student), because working on joint tasks typically leads to compliance to the social norm of cooperation (Campbell, 1975; Ullmann-Margalit, 1977). Research on social dilemmas even observes substantial cooperation on joint tasks when monetary temptations are linked to noncooperative behavior (Marwell \& Ames, 1979, 1980; Orbell, Schwartz-Shea, \& Simmons, 1984; Orbell, van de Kragt, \& Dawes, 1988).

We either activated outside of awareness (primed) or consciously induced the goal to be either combative or accommodating. No-goal control groups for the nonconscious and the conscious goal conditions were created by using neutral words in the priming procedure or by not inducing any goal, respectively. Being combative in a joint task obviously violates the social norm of cooperation, whereas being accommodating conforms to this norm. Consistent with research on goal priming, individuals in the present study should behave in line with their goals and thus be more combative in the combative goal condition as compared to the accommodating goal condition, no matter whether the combative and accommodating goals are activated outside of awareness or consciously induced. However, individuals in the norm-violating (combative) goal condition should experience greater negative affect when this goal is nonconsciously activated as compared to consciously induced. This difference in affective experience should not emerge in the norm-conforming (accommodating) conditions (i.e., negative affect is low for nonconsciously activated as well as consciously induced normconforming goals). Moreover, the behavior and affective responses of individuals in the control conditions should resemble those of the norm-conforming (accommodating) conditions, as trying to be accommodating is the default response in joint tasks. Finally, negative affect should be linked to norm-violating (combative) behavior more strongly in participants with nonconscious goals than in those who had been assigned conscious goals (and thus are able to explain their combative behavior by their intentions).

\section{Methods}

\section{Participants and procedure}

Seventy-nine undergraduate students ( 48 females and 31 males) participated for course credit. They were randomly assigned to one of six conditions in a 2 (awareness of goal: nonconscious vs. conscious) $\times 3$ (content of goal: norm-violating, norm-conforming, and control) design.

\section{Behavioral task}

Pairs of participants were asked into separate, but adjacent soundproof cubicles. Students of each pair were requested to work with each other on a supposedly new interactive version of the Thematic Apperception Test (TAT) that required generating joint stories for two original TAT pictures (Murray, 1943; Picture 1: Two women watching a man plowing the field; Picture 2: A young boy staring at his fiddle). The new instrument was supposed to be administered on the Internet, and this is why participants would be taking the TAT via an intranet set up between two separate cubicles.

Participants had a couple of minutes to look at the first picture presented at their individual computer, and then they wrote about it and sent their story to the partner. Thereafter, they received the partner's story (the same scripted story was given to all participants). After studying their partner's story, they wrote and sent their feedback to the partner. They had been told that their feedback could include any thoughts on what their partner wrote or any additional ideas about the picture.

\section{Conscious goal manipulation}

After writing their first story and giving feedback to the partner's first story (i.e., right before the second picture appeared on the screen), half of the participants were assigned to the conscious goal condition that had three levels: a norm-violating (combative) goal, a norm-conforming (accommodating) goal, and a respective no-goal control condition. Participants in the control condition did not receive any goal instructions. They were simply told to write an initial story to the second picture, and then give feedback to the partner's story to the second picture.

Participants in the norm-violating and norm-conforming goal conditions were instructed to behave in a certain way for the presumed purpose to reduce unwanted variance from individual differences in interaction goals. Participants in the norm-violating goal condition were told, "So when you are working with your partner to generate a story together for the next picture, please be assertive and stand up for yourself!" Participants in the norm-conforming goal condition read instead, "..., please be accommodating and be receptive to your partner's concerns!" Like in the control 
condition, participants then wrote an initial story to the second picture and gave feedback to the partner's presumed story to the second picture. The partner's story read:

"The kid doesn't look too happy-why? I imagine a lot of people who see this picture think it's all about violin lessons, and that the boy wants to be a musician. I think ... he's training to be a magician. He's staring at the violin because he wants to make it levitate. He's unhappy because he's frustrated because he's thinking so hard and the bow is barely moving. Look carefully at the bow-you'll notice that one end of it seems to be floating just above the table."

\section{Nonconscious goal manipulation}

The other half of the participants were assigned to the nonconscious goal condition that again had three levels: a norm-violating (combative) goal, a norm-conforming (accommodating) goal, and a respective no-goal control condition. Right before the second picture, all nonconscious goal participants were given an interspersed classification task presumably checking on their vigilance. They were asked to indicate by button press responses whether brief flashes appeared either on the left or right side of the screen marked by a fixation cross (Chartrand \& Bargh, 1996; Kawada, Oettingen, Gollwitzer, \& Bargh, 2004). There were four blocks of 35 trials. In each trial, the flashed word randomly succeeded the one prior by either 2, 3, 4, 5, 6, or $7 \mathrm{~s}$. Each stimulus word was presented for $60 \mathrm{~ms}$ and then was immediately followed by a $60 \mathrm{~ms}$ masking string of letters in the same location. The stimulus words and respective masks appeared randomly in one of the four quadrants of the screen. In that the location and timing of the presented words were random, presented for only $60 \mathrm{~ms}$, and followed immediately by a mask participants did not become conscious of the semantic content of the stimulus words as indicated during extensive probing at the end of the experiment.

For all four blocks of 35 trials, the no-goal control participants repeatedly received five neutral words (house, building, calendar, sidewalk, and plant). In the norm-violating and norm-conforming nonconscious goal conditions, the first two blocks of 35 trials consisted of the same neutral words. For the second two blocks, participants in the normviolating nonconscious goal condition were shown five combative words (i.e., stand up, assert, resist, uphold, and affirm), while those in the norm-conforming nonconscious goal condition were shown five accommodating words (i.e., accommodate, go along, comply, give in, and succumb).

After this classification task, all participants in the three nonconscious goal conditions went on to the second picture. Like those in the three conscious goal conditions, they wrote an initial story to the second picture and gave feedback to the partner's presumed second story.

\section{Measure of affect}

Following the mock TAT, participants in all conditions were instructed to complete a questionnaire assessing their feelings at that moment. In the tradition of research on the effects of accidental versus intentional transgressions on affect (McGraw, 1987), the present study focused on assessing negative affect only. Participants had to circle a number on a scale ranging from 1 (not at all) to 7 (extremely), indicating the extent to which they were feeling irritated, uneasy, tense, anxious, annoyed, on edge, angry, frustrated, and aggressive. The experimenter also assessed participants' suspicion of the cover story through several openended questions. Finally, participants were fully debriefed and thanked for their participation.

\section{Results}

\section{Nonconscious and conscious goal effects on behavior}

Two raters, blind to the experimental conditions, coded the content of the feedback participants gave to their partner. The baseline feedback (comments on the partner's story to the first picture) and the post goal feedback (comments on the partner's story to the second picture) were coded on a 7-point scale ranging from not at all (1) to very much (7) according to the degree to which participants were combative and asserted their own opinions. Raters used a coding scheme that provided examples of combativeness and assertiveness for each level of the 7-point scale. A " 1 " was coded when participants fully accepted what their partner had written and suggested to have their partner's ideas dominate the story, while a "7" was coded when participants openly disagreed with their partner's ideas and suggested to have their own ideas dominate the story. Interrater reliability was high $(r=.87)$.

A 2 (awareness of goal: nonconscious vs. conscious) $\times 3$ (content of goal: norm-violating, norm-conforming, and no goal) ANOVA was conducted on post-goal combativeness of comments to the partner controlling for baseline (pregoal) combativeness. There was a main effect of goal content, $F(2,77)=6.30, p<.01$. Participants in the normviolating goal conditions, $M=1.97, S D=0.40$, were more combative than those in the norm-conforming goal conditions, $M=0.15, S D=0.41, p=.002$, and the no-goal control conditions, $M=0.33, S D=0.42, p=.006$ (Fig. 1). The difference between the norm-conforming goal conditions and the no-goal control conditions was not significant, $F<1$, ns. Finally, there was no main effect of awareness of goal $(F<1)$ and no interaction effect of awareness of goal with content of goal, $F(1,78)=1.41, p=.25$.

Among the nonconscious goal conditions, a planned contrast revealed that participants were more combative in the norm-violating condition $(M=1.41, S D=0.59)$ than in the other conditions (norm-conforming $M=0.80$, $S D=0.62$; no goal $M=0.21, S D=0.56$ ), though this effect was only marginally significant, $F(1,30)=1.75, p<.10$ (one-tailed). Among the conscious goal conditions, participants were also more combative in the norm-violating condition $(M=2.32, S D=0.54)$ than in the other conditions 


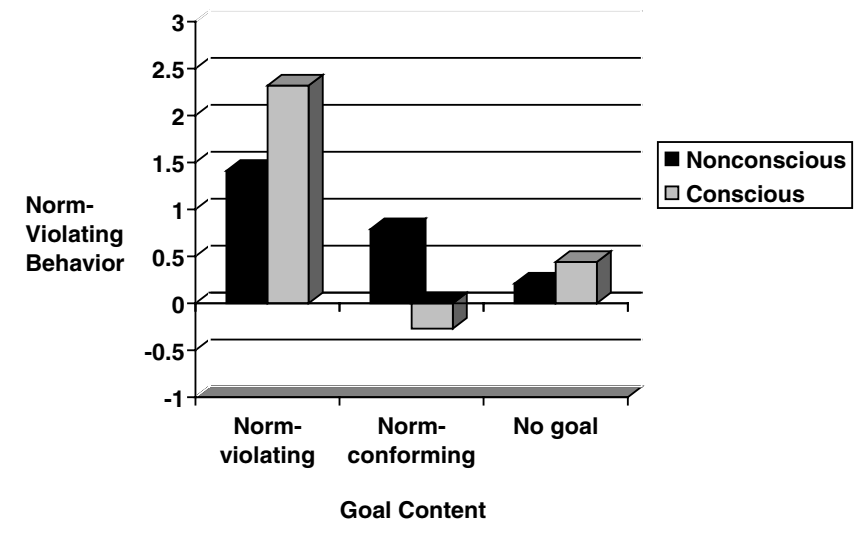

Fig. 1. Mean combative (i.e., norm-violating) behavior by goal content and goal awareness.

(norm-conforming $\quad M=-0.27, \quad S D=0.54 ; \quad$ no goal $M=0.44, S D=0.62) ; F(1,41)=11.55, p<.01$.

\section{Nonconscious and conscious goal effects on negative affect}

Principal Components Analysis of emotions on the mood inventory yielded one factor with an Eigenvalue greater than 1.0 (which accounted for $71 \%$ of the variance in emotion ratings). Therefore, we summed responses to the 9 negative emotion items to create an index of negative affect (Cronbach's $\alpha=.95$ ).

A 2 (awareness of goal: nonconscious vs. conscious) $\times 3$ (content of goal: norm-violating, norm-conforming, and no goal) ANOVA revealed a main effect of goal awareness, indicating that nonconscious goal participants reported significantly more negative affect, $M=25.52, S D=14.11$, than conscious goal participants, $M=17.68, \quad S D=8.59$; $F(1,78)=10.03, p=.002$. This main effect was qualified by a significant interaction with goal content, $F(2,77)=3.09$, $p<.05$. Participants in the nonconscious norm-violating goal condition reported more negative affect, $M=30.34$, $S D=15.78$, than participants in the conscious norm-violating goal condition, $M=14.42, S D=7.84 ; t(78)=3.53$, $p=.002$. There were no significant differences between nonconscious and conscious goals in the norm-conforming goal condition, $M=22.32, S D=7.84$ vs. $M=21.66$, $S D=9.70 ; t<1$, and in the no-goal control condition, $M=23.81, \quad S D=16.23 \quad$ vs. $\quad M=16.39, \quad S D=5.92$; $t(52)=1.52, p=.16$ (Fig. 2).

Although the difference in negative affect between nonconscious and conscious control participants was not significant, there was a slight tendency for nonconscious control participants to experience more negative affect than conscious control participants. It seems reasonable to assume that even though a norm-conforming (accommodating) response is the default in the no-goal control condition, control participants represent a mixture of participants of which a minority does not behave in a norm-conforming way.

We also explored the relation between combative behavior and negative affect in the norm-violating conscious

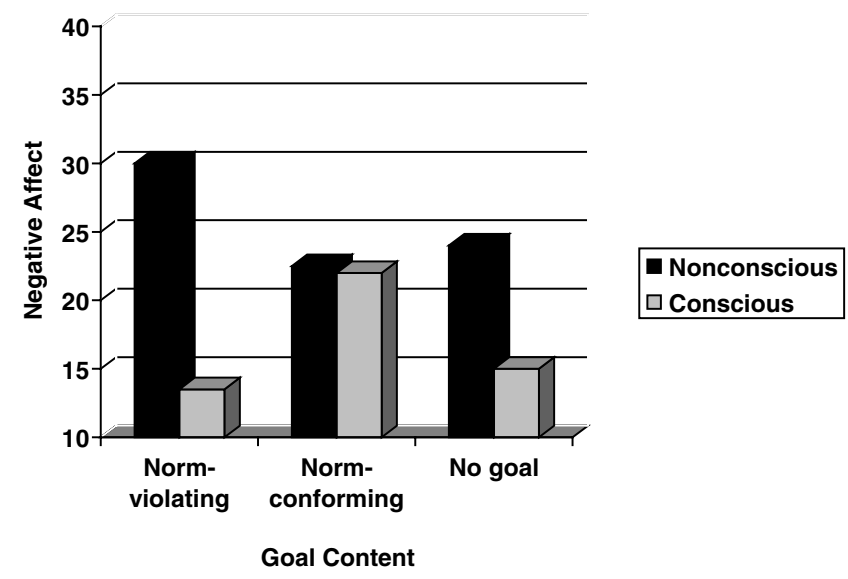

Fig. 2. Mean negative affect by goal content and goal awareness.

versus nonconscious goal conditions, hypothesizing that the relation should be stronger in the nonconscious condition than in the conscious condition. We estimated a General Linear Model with negative affect as the dependent variable. Awareness of goal, amount of combative (normviolating) behavior, and the interaction of these two variables were the predictors. We observed a significant interaction effect, $F(1,22)=4.93, p<.05$, indicating a steeper slope depicting the relation between combative behavior and negative affect in the nonconscious than in the conscious goal condition.

\section{Discussion}

In line with previous research, we observed similar effects of nonconscious and conscious goals on goaldirected behavior. Irrespective of whether combative (norm-violating) goals were activated outside of awareness or consciously assigned, they led to more assertive behavior in a cooperative task than accommodating goals and no goals. Affective responses to goal-directed behavior, to the contrary, differed between nonconscious and conscious goals given that the goal pursuit was norm-violating (combative). Apparently, individuals who were combative in the conscious condition had an excuse - they could explain and thus justify their behavior by pointing to the goal assigned by the experimenter thereby easing negative feelings associated with breaking norms. Participants in the nonconscious goal condition did not have access to such an excuse. Not surprisingly, then, for the latter individuals negative affect was linked to the degree of combative behavior.

Our interpretation of the present findings is based on the assumption that participants in the three goal content conditions (i.e., norm-violating, norm-conforming, no goal) experienced the same strong norm to be accommodating. One could argue, however, that the conscious norm-violating more so than the conscious norm-conforming goal weakened the norm of being accommodating, so that this norm was perceived as less in place or obligating. Accordingly, participants in the conscious norm-violating goal 
condition may have experienced less negative affect not because they had an excuse due to their conscious awareness of their goal, but because they felt that the norm to be accommodating did no longer apply.

\section{A follow-up experiment: Different norm perceptions as an alternative explanation?}

We tested whether the experimental paradigm of the previous study indeed activates the norm of being accommodating rather than the norm of being combative, and whether norm perception was modified by the norm-conforming versus the norm-violating goals assigned by the experimenter. We described each of the three conditions of the paradigm to three randomly chosen groups of undergraduates and asked them to indicate to what extent (a) one should be accommodating and receptive to the other person's concerns, and (b) one should assert one's own ideas against the other person's concerns. We expected that participants endorse the norm of being accommodating to a higher degree than the norm of being combative, and that this difference is not affected by learning about the experimenter's goal assignments.

\section{Methods}

\section{Participants and procedure}

Seventy-one undergraduates (43 females and 28 males) participated for course credit. They were randomly assigned to one of three conditions (content of goal: normviolating, norm-conforming, control).

\section{Scenarios presented}

In the control condition, participants were asked to imagine themselves as the main character of a vignette that described in detail the events that participants in the control condition of the previous experiment had actually experienced. Specifically, the vignette described a participant in a social psychology experiment in which the task was to conjointly write creative stories with an anonymous partner participant in response to the two TAT-pictures used in the previous experiment. It was further explained that during the work on their joint task, the partner expressed quite different ideas about the pictures presented. In the norm-conforming goal condition, the vignette depicted the experimenter as asking each pair of participants to be accommodating and receptive to the ideas of the partner, whereas in the norm-violating condition, the experimenter was depicted as asking to be assertive in expressing their own individual thoughts and to stand up for themselves.

\section{Norm perception}

Following research on the assessment of norm perception (Beck \& Opp, 2001; Jasso \& Opp, 1997), we then asked: "How do you think that one should act in such a situation? What would be the social norm?" Participants responded to this question by checking the answer scales (ranging from $1=$ not at all to $7=$ very) of the following two items: "One should accommodate one's partner and respect and integrate the partner's ideas," and "One should assertively express one's own ideas."

\section{Results and discussion}

We computed a 2 within (social norm: accommodating vs. combative) $\times 3$ between (content of goal: norm-violating, norm-conforming, no goal) ANOVA on participants' ratings. A highly significant main effect of social norm emerged, $F(1,68)=33.22, p<.001$, indicating that participants perceived the described situation as governed by the social norm of being accommodating $(M=5.16, S D=1.63)$ rather than being combative $(M=3.08, S D=1.64)$. This main effect was not qualified by an interaction effect with the goal content factor, $F(2,68)=.04, n s$. Indeed, the ratings of the accommodating norm were close to identical in the three goal conditions (norm-violating: $M=5.06$, $S D=1.88$, norm-conforming: $5.17, S D=1.43$, control: 5.26 , $S D=1.57$ ), as were the ratings of the combative norm (norm-violating: $M=3.10, S D=1.71$, norm-conforming: $M=3.09, S D=1.62$, control: $M=3.04, S D=1.66$ ).

These findings suggest that the experimental paradigm used in our first experiment activated the norm of being accommodating towards the partner, and that this norm was equally well established in the different conscious goal conditions. Accordingly, the fact that nonconscious normviolating goals produced strong negative affect can be confidently interpreted as the result of participants' recognition of having broken the social norm of being accommodating. In contrast, conscious norm-violating goals produced little negative affect, because participants consciously intended to break the social norm of being accommodating, and thus readily explained their non-normative behavior by referring to their intention (McGraw, 1987).

\section{General discussion}

\section{Implications for research on goal pursuit}

Understanding similarities and differences between nonconscious and conscious goal pursuits require differentiating between outcomes of goal pursuit on the one hand, and the experience of goal pursuit on the other. With respect to outcomes we observed similarities in line with prior research (summaries by Chartrand \& Bargh, 2002; Fitzsimons \& Bargh, 2003; Gollwitzer \& Bargh, 2005), whereas with respect to the experience of one's goal pursuit we observed differences. When participants behaved combatively in a cooperative task on the basis of a nonconscious goal, they reported more negative affect than participants who behaved the same on the basis of a respective conscious goal. Behaving combatively in a cooperative situation is nonnormative and thus needs to be explained. 
If norm-violating behavior is backed up by a respective conscious goal, the individual can readily explain why she is breaking the norm. She only needs to refer to the conscious goal and no negative feelings are experienced. To the contrary, when a nonconsciously activated goal elicits behavior that is breaking a norm, the individual behaves nonnormatively without such a ready excuse and thus negative feelings will ensue.

It is important to recognize that nonconscious and conscious goal pursuits do not differ in their affective consequences in general. Chartrand (2004) reports similar moods in individuals who engaged in easy vs. difficult (task) goals no matter whether goal striving was instigated nonconsciously or consciously. Rather, nonconscious and conscious goal pursuits produce different affect only if explanations of one's goal-directed behavior are called for.

\section{Future research}

The present research focuses on conscious goals assigned by the experimenter. Therefore, we do not know yet whether similar findings emerge for self-set goals. However, the lack of differences reported in the goal literature between processes and outcomes of self-set versus assigned goals (summaries by Locke \& Latham, 1990; Oettingen \& Gollwitzer, 2001) suggests that both kinds of goals qualify as explanations of nonnormative behavior equally well. Also, we examined one specific social norm only (i.e., the norm of being accommodating), but future research might explore whether nonconscious goal pursuit against other social (e.g., respecting people's possessions) or nonsocial norms (e.g., working conscientiously) leads to negative affective experiences. Finally, the present research targets negative affect, but the analysis of positive affect as a consequence of conscious vs. nonconscious goal pursuits seems also promising. For instance, having performed nonnormative kindness on the basis of nonconscious goals may create stronger positive feelings as compared to showing such kindness on the basis of conscious goals. Whenever positive behavior or outcomes have to be explained (e.g., one finds oneself overly generous), stronger positive feelings should emerge with nonconscious compared to conscious goal pursuit. This prediction is supported by Wilson, Centerbar, Kermer, and Gilbert (2005) showing that the understanding (i.e., reduction of uncertainty) of positive events makes them less enjoyable. They inflicted unexpected positive events on people (e.g., receiving a gift) and observed that positive affect is experienced dependent on the degree of uncertainty of these events. The present analysis suggests that pleasure will increase also in people who produce nonnormative (unexpected) positive events, given that these people operate on the basis of a respective nonconscious goals.

\section{Conclusion}

Goal pursuit may implicate two parts of the self, the "I" and the "Me." According to William James (1899), the
"Me" is composed of all aspects of the self that can be observed and known. The "I," on the other hand, is the actor, or what Baumeister (1998) calls the executive self (i.e. the part of the self that sets goals and implements them). The present research suggests that conscious versus nonconscious goal pursuits are similar in aspects that are instigated by the "I". Involvement of the "Me," however, produces differences. In other words, the acting on a goal is similar no matter whether one is aware (conscious) or unaware (nonconscious) of that goal; the interpretation of the goal pursuit at hand, however, differs between consciously set and nonconsciously activated goals as the former is associated with knowing of the goal at hand whereas the latter is not.

\section{References}

Aarts, H., Gollwitzer, P. M., \& Hassin, R. R. (2004). Goal contagion: Perceiving is for pursuing. Journal of Personality and Social Psychology, $87,23-37$.

Atkinson, J. W. (1957). Motivational determinants of risk-taking behavior. Psychological Review, 64, 359-372.

Bandura, A. (1997). Self-efficacy: The exercise of control. New York: W.H. Freeman.

Bargh, J. A. (1990). Auto-motives: Preconscious determinants of social interaction. In E. T. Higgins \& R. M. Sorrentino (Eds.), Handbook of motivation and cognition (Vol. 2, pp. 93-130). New York: Guilford Press.

Bargh, J. A., \& Gollwitzer, P. M. (1994). Environmental control of goaldirected action: Automatic and strategic contingencies between situations and behavior. In W. Spaulding (Ed.), Nebraska symposium on motivation (Vol. 41, pp. 71-124). Lincoln: University of Nebraska Press.

Bargh, J. A., Gollwitzer, P. M., Lee-Chai, A., Barndollar, K., \& Troetschel, R. (2001). The automated will: Nonconscious activation and pursuit of behavioral goals. Journal of Personality and Social Psychology, 81, 1014-1027.

Baumeister, R. F. (1998). The self. In D. T. Gilbert, S. T. Fiske, \& G. Lindzey (Eds.), The handbook of social spsychology (Vol. 1, 4th ed., pp. 680 740). New York: McGraw Hill.

Baumeister, R. F., \& Vohs, D. K. (Eds.). (2004). Handbook of self-regulation. Research, theory, and applications. New York: Guilford Press.

Beck, M., \& Opp, K.-D. (2001). Der faktorielle Survey und die Messung von Normen [The factorial survey and the assessment of norms]. Kölner Zeitschrift für Soziologie und Sozialpsychologie, 53, 283-306.

Campbell, D. (1975). On the conflicts between biological and social evolution and between psychological and moral tradition. American Psychologist, 30, 1103-1126.

Cantor, N., \& Kihlstrom, J. F. (1987). Personality and social intelligence. Englewood Cliffs, NJ: Prentice-Hall.

Carver, C. S., \& Scheier, M. F. (1981). Personality and self-regulation: A control theory approach to human behaviors. New York: Springer.

Chartrand, T. L. (2004). Mystery moods and perplexing performance: Consequences of succeeding and failing at a nonconscious goal. (submitted).

Chartrand, T. L., \& Bargh, J. A. (1996). Automatic activation of impression formation and memorization goals: Nonconscious goal priming reproduces effects of explicit task instructions. Journal of Personality and Social Psychology, 71, 464-478.

Chartrand, T. L., \& Bargh, J. A. (2002). Nonconscious motivations: Their activation, operation, and consequences. In A. Tesser, D. Stapel, \& J. Wood (Eds.), Self and motivation: Emerging psychological perspectives (pp. 13-41). Washington, DC: American Psychological Association Press.

Chartrand, T. L., Cheng, C. M., \& Tesser, A. (2001). Consequences of failing at nonconscious goals for self-enhancement and stereotyping. Unpublished manuscript. 
Chen, S., Lee-Chai, A. Y., \& Bargh, J. A. (2001). Relationship orientation as a moderator of the effects of social power. Journal of Personality and Social Psychology, 80, 173-187.

Deci, E. L., \& Ryan, R. M. (1985). Intrinsic motivation and self-determination in human behavior. New York: Plenum.

Fitzsimons, G. M., \& Bargh, J. A. (2003). Thinking of you: Nonconscious pursuit of interpersonal goals associated with relationship partners. Journal of Personality and Social Psychology, 84, 148-164.

Freedman, J. L. (1970). Transgression, compliance, and guilt. In J. Macaulay \& L. Berkowitz (Eds.), Altruism and helping behavior (pp. 155-162). New York: Academic Press.

Freedman, J. L., Wallington, S. A., \& Bless, E. (1967). Compliance without pressure: The effect of guilt. Journal of Personality and Social Psychology, 7, 117-124.

Gollwitzer, P. M. (1990). Action phases and mindsets. In R. M. Sorrentino \& E. T. Higgins (Eds.), Handbook of motivation and cognition (Vol. 2, pp. 53-92). New York: Guilford Press.

Gollwitzer, P. M. (1999). Implementation intentions: Strong effects of simple plans. American Psychologist, 54, 493-503.

Gollwitzer, P. M., \& Bargh, J. A. (2005). Automaticity in goal pursuit. In A. Elliot \& C. Dweck (Eds.), Handbook of competence and motivation (pp. 624-646). New York: Guilford Press.

Hamilton, D. L., Katz, L. B., \& Leirer, V. O. (1980). Organizational processes in impression formation. In R. Hastie, T. M. Ostrom, R. S. Ebbesen, E. B. Wyer, D. L. Hamilton, \& D. E. Carlston (Eds.), Person memory: The cognitive biases of social perception (pp. 121-153). Hillsdale, NJ: Lawrence Erlbaum Associates.

Heckhausen, H. (1977). Achievement motivation and its constructs: A cognitive model. Motivation and Emotion, 4, 283-329.

James, W. (1890). The principles of psychology. Oxford England: Holt.

Jasso, G., \& Opp, K.-D. (1997). Probing the character of norms. American Sociological Review, 62, 947-964.

Lewin, K. (1926). Untersuchungen zur Handlungs- und Affektpsychologie. Psychologische Forschung, 2, 65-140.

Locke, E. A., \& Latham, G. P. (1990). A theory of goal setting and task performance. Englewoods Cliffs, NJ: Prentice Hall.

Kawada, C. L. K., Oettingen, G., Gollwitzer, P. M., \& Bargh, J. A. (2004). The projection of implicit and explicit goals. Journal of Personality and Social Psychology, 86, 545-559.

Marwell, G., \& Ames, R. (1979). Experiments in the provision of public goods: 1. Resources, interest, group size and the free rider problem. American Journal of Sociology, 84, 1335-1360.
Marwell, G., \& Ames, R. (1980). Experiments in the provision of public goods: 2. Provision points, stakes, experience and the free rider problem. American Journal of Sociology, 85, 926-937.

McGraw, K. M. (1987). Guilt following transgression: An attribution of responsibility approach. Journal of Personality and Social Psychology, $53,247-256$.

Murray, H. A. (1943). Thematic Apperceptive Test Manual. Cambridge: Harvard University Press.

Noel, A. R. C. (1973). Transgression-compliance: A failure to confirm. Journal of Personality and Social Psychology, 27, 151-153.

Oettingen, G., \& Gollwitzer, P. M. (2001). Goal setting and goal striving. In A. Tesser \& N. Schwarz (Eds.), Intraindividual processes (pp. 329 347). Oxford: Blackwell

Orbell, J., Schwartz-Shea, P., \& Simmons, R. (1984). Do cooperators exit more readily than defectors. American Political Science Review, 78, 147-162.

Orbell, J., van de Kragt, A., \& Dawes, R. (1988). Explaining discussion-induced cooperation. Journal of Personality and Social Psychology, 54, 811-819.

Riketta, M., \& Dauenheimer, D. (2003). Anticipated success at unconscious goal pursuit: Consequences for mood, self-esteem, and the evaluation of a goal-relevant task. Motivation and Emotion, 27, 327-338.

Roseman, I. J. (1984). Cognitive determinants of emotion: A structural theory. In P. Shaver (Ed.), Review of personality and social psychology (Vol. 5, pp. 37-63). Beverly Hills, CA: Sage.

Shah, J. Y. (2003). Automatic for the people: How representations of significant others implicitly affect goal pursuit. Journal of Personality and Social Psychology, 84, 661-681.

Tesser, A., Martin, L. L., \& Cornell, D. P. (1996). On the substitutability of self-protective mechanisms. In P. M. Gollwitzer \& J. A. Bargh (Eds.), The psychology of action: Linking cognition and motivation to behavior (pp. 48-68). New York: Guilford Press.

Tolman, E. C. (1925). Purpose and cognition: The determinants of animal learning. Psychological Review, 32, 285-297.

Ullmann-Margalit, E. (1977). The emergence of norms. Oxford, England: Oxford University Press.

Weiner, B., Amirkhan, J., Folkes, V. S., \& Verette, J. A. (1987). An attributional analysis of excuse giving: Studies of naïve theory of emotion. Journal of Personality and Social Psychology, 52, 316-324.

Wicker, F. W., Payne, G. C., \& Morgan, R. D. (1983). Participant descriptions of guilt and shame. Motivation and Emotion, 7, 25-39.

Wilson, T. D., Centerbar, D. B., Kermer, D. A., \& Gilbert, D. (2005). The pleasures of uncertainty: Prolonging positive moods in ways people do not anticipate. Journal of Personality and Social Psychology, 88, 5-21. 